ARTICLE

\title{
Controlling the volatility of the written optical state in electrochromic DNA liquid crystals
}

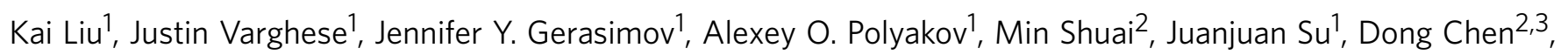
Wojciech Zajaczkowski ${ }^{4}$, Alessio Marcozzi ${ }^{1}$, Wojciech Pisula4,5, Beatriz Noheda1, Thomas T.M. Palstra', Noel A. Clark ${ }^{2} \&$ Andreas Herrmann ${ }^{1}$

Liquid crystals are widely used in displays for portable electronic information display. To broaden their scope for other applications like smart windows and tags, new material properties such as polarizer-free operation and tunable memory of a written state become important. Here, we describe an anhydrous nanoDNA-surfactant thermotropic liquid crystal system, which exhibits distinctive electrically controlled optical absorption, and temperaturedependent memory. In the liquid crystal isotropic phase, electric field-induced colouration and bleaching have a switching time of seconds. Upon transition to the smectic liquid crystal phase, optical memory of the written state is observed for many hours without applied voltage. The reorientation of the DNA-surfactant lamellar layers plays an important role in preventing colour decay. Thereby, the volatility of optoelectronic state can be controlled simply by changing the phase of the material. This research may pave the way for developing a new generation of DNA-based, phase-modulated, photoelectronic devices.

\footnotetext{
${ }^{1}$ Zernike Institute for Advanced Materials, University of Groningen, Nijenborgh 4, 9747 AG Groningen, The Netherlands. ${ }^{2}$ Department of Physics and Soft Materials Research Center, University of Colorado, Boulder, Colorado 80309, USA. ${ }^{3}$ Institute of Process Equipment, College of Chemical and Biological Engineering, Zhejiang University, Hangzhou 310027, China. ${ }^{4}$ Max Planck Institute for Polymer Research, Ackermannweg 10, 55128 Mainz, Germany. ${ }^{5}$ Department of Molecular Physics, Faculty of Chemistry, Lodz University of Technology, Zeromskiego 116, 90-924 Lodz, Poland. Correspondence and requests for materials should be addressed to N.A.C. (email: noel.clark@colorado.edu) or to A.H. (email: a.herrmann@rug.nl).
} 
E: lectrochromism, or the electrical control of a material's absorption of light ${ }^{1-3}$, has led to the development of many technological applications that span dynamic tinting windows and mirrors, colour changing displays, smart cards and e-paper ${ }^{4}$. Several distinct classes of materials have been extensively investigated for their usefulness in electrochromic applications, including organic systems (for example, bipyridylium salts) ${ }^{5-9}$, electroactive conducting polymers (for example, polyaniline, polythiophenes) ${ }^{1,10-13}$, metal-organic systems (for example, Prussian blue, Fe-terpyridines coordination polymer, Zn-pyrazolate metal-organic frameworks) ${ }^{14-17}$ as well as inorganic systems based on transition metal oxides (for example, $\left.\mathrm{WO}_{3}\right)^{18-21}$. Despite these advances, there is a strong need for more accessible and easily processable materials with a greater degree of tunability of electrochromic behaviour. Challenges to be achieved include control over the duration of an electronic state in the absence of electrical input or in response to temperature changes. Therefore, the development of new electrochromic materials is an important goal.

Liquid crystals (LCs) are phases of soft condensed matter in which varying degrees of partial orientational and positional ordering result in an enormous variety of functional properties $^{22,23}$. The flexibility inherent in LC physical organization, along with that of organic molecular electronic structures for redox-active functionality, combine to form an attractive basis for pursuing electrochromism ${ }^{24-26}$. Furthermore, this flexibility in LC ordering may lead to novel electrochromic behaviours different from those of disordered electrochromic materials.

Thus far, the unique electrical characteristics of DNA have prompted the utilization of DNA in the fields of materials and nanotechnology ${ }^{27-29}$. However, little effort has been invested in studying the electrochromic properties of DNA, which is appealing as an electrochromic material due to its ubiquity and uniform distribution of redox-active sites (nucleobases) along its polymer backbone ${ }^{30-32}$. Recently, we have prepared a series of thermotropic LCs based on DNA-surfactant complexes that are produced by a simple preparation protocol ${ }^{33,34}$. Phase transition temperatures from the isotropic liquid phase to the LC phase to the crystalline phase can be modulated over a broad temperature range by controlling the average length of the cationic surfactant that is complexed to the negatively charged single-stranded nucleic acid molecule.

Here, we report the development of DNA-LC-based electrochromic devices that are readily switchable between the coloured and colourless states in the isotropic phase. The rate of colouration decay can be regulated by adjusting the phase of the DNA-surfactant complex, the length of the DNA oligomer and the identity of the complexing surfactant. A colour impression can thus be preserved for several hours in the absence of applied voltage if the temperature of the system is adjusted to accommodate the LC phase or the crystalline phase. Moreover, in response to temperature changes above the clearing temperature, immediate colour loss is observed. This phenomenon allows for controlling the volatility of stored information in a simple and practical manner and might allow the fabrication of smart tags with clock and thermometer functions.

\section{Results}

Preparation and characterization of DNA-surfactant LCs. DNA-surfactant materials were prepared by electrostatic complexation of single-stranded oligonucleotides (6mer, $14 \mathrm{mer}$,
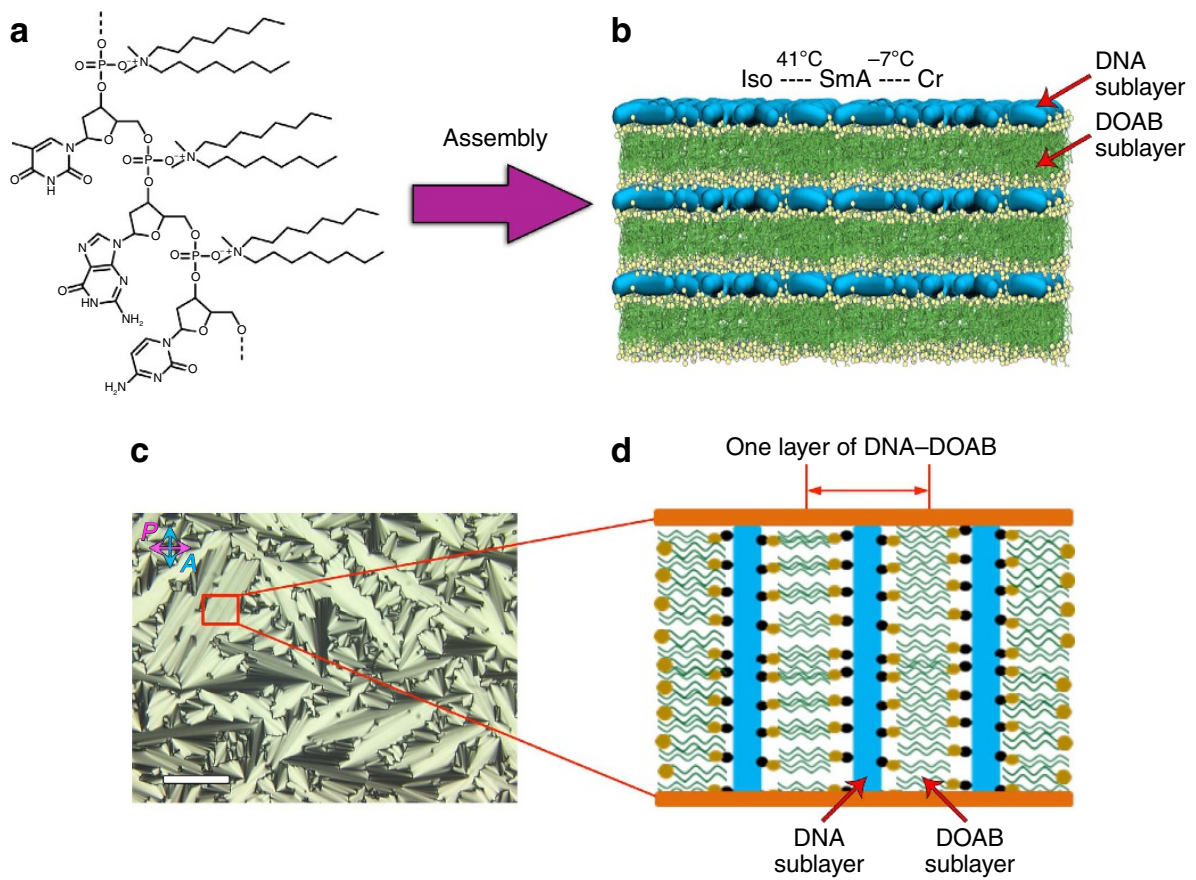

Figure 1 | Schematic illustration of the DNA-surfactant complex formation. (a) Molecular structure of DNA-surfactant complex using dioctyldimethylammonium bromide $(D O A B)$ as a representative cationic surfactant that electrostatically interacts with the oligonucleotide backbone. With increasing temperature, the DNA-surfactant complexes transition from crystalline state to the LC state and further to the isotropic liquid state. (b) The lamellar bilayer structure in the LC phase is made of one sublayer of single-stranded DNA and one sublayer of interdigitated surfactants, where the phosphate groups of DNA electrostatically interact with the cationic head groups of surfactants. (c) A polarized optical microscopy (POM) image of the DNA-surfactant LC phase in a LC cell (here taking 14 mer DNA-DOAB as a representative complex, $25^{\circ} \mathrm{C}$, cell gap $\sim 6.8 \mu \mathrm{m}$ ) shows well-defined focal-conic textures of the smectic phase. Scale bar, $100 \mu \mathrm{m}$. (d) An illustration of the alignment of the DNA-surfactant LC in the cell shows that the DNA-surfactant smectic layers are vertical to the ITO-coated glass slide surface. In $\mathbf{d}$, black ball represents phosphate anions of oligonucleotide and yellow ball represents ammonium cations of surfactant. 
22mer and 50mer) with a single type of cationic surfactant (dioctyldimethylammonium bromide (DOAB), didecyldimethylammonium bromide (DEAB) and didodecyldimethylammonium bromide (DDAB)) or with a two-component mixture of surfactants $(\mathrm{DOAB}+\mathrm{DEAB}$ and $\mathrm{DEAB}+\mathrm{DDAB})$. DNA-surfactant LCs were obtained according to a previously published protocol ${ }^{33}$ that requires precipitating the DNA out of solution using the cationic surfactant, extracting the solid product by centrifugation, and lyophilizing the complex to remove any excess water. The resulting product exhibits discrete phase transitions from the isotropic liquid, to the LC and crystalline phases at temperatures characteristic of the material. For example, the DNA-DOAB complex exhibits a smectic A LC phase between -7 and $41^{\circ} \mathrm{C}$ (Fig. 1 and Supplementary Fig. 1). In this lamellar LC phase, each repeating layer consists of a cationic surfactant bilayer that electrostatically interacts with an anionic oligonucleotide sublayer $^{33}$. Within the DNA sublayer, the single-stranded oligonucleotide chains are randomly oriented, without any positional or orientational order. Long-range periodic layer structures in the LC phase have been directly visualized by freeze-fracture transmission electron microscopy (Supplementary Fig. 2). The degree of crystallinity was also investigated by wideangle X-ray scattering. When the DNA-DOAB sample is heated above $41{ }^{\circ} \mathrm{C}$, the X-ray scattering peak that was observed in the LC phase disappears, indicating a transition to the disordered liquid state (Supplementary Fig. 1b). If the sample is cooled below $-7^{\circ} \mathrm{C}$, a series of sharp, high-intensity diffraction peaks provide evidence of crystallinity (Supplementary Fig. 1d). The phase transition temperatures of DNA-surfactant complexes can be controlled over a wide temperature range by varying the alkyl chain length of surfactants and using mixtures of surfactants complexed to the DNA (Supplementary Fig. 3). To study the optoelectronic behaviour of the samples, an LC cell was used that consists of two indium tin oxide (ITO)-coated glass plates separated by a gap of $\sim 6.8 \mu \mathrm{m}$. The LC cell was filled with the sample in the isotropic state by capillary action. When the samples were cooled to the smectic LC phase, focal-conic domains were observed by polarizing optical microscopy (POM; Fig. 1c). In these homogenous alignments, the smectic layers of the DNA-surfactant LC were oriented perpendicular to the electrode surface (Fig. 1d).

Electrochemical properties of DNA-surfactant LCs. The redox properties of the DNA-surfactant materials were examined by cyclic voltammetry measurements. In the bulk LC state, the electrochemical spectrum of the DNA-surfactant complex was acquired in a two-ITO-electrode LC cell at $25^{\circ} \mathrm{C}$, where direct current (d.c.) electric field was applied in the direction of the DNA-surfactant smectic layers (Fig. 2, red curve). Indeed, reversible anodic oxidation and cathodic reduction processes of DNA were observed at the half-wave potentials of +2.4 and $-2.15 \mathrm{~V}$, respectively. Increasing the temperature to the isotropic phase of the LC material (Fig. 2, black curve), similar redox behaviours were observed, but at lower half-wave potentials of +2.07 and $-1.68 \mathrm{~V}$. This indicates that the activation of nucleobase in the isotropic phase is more efficient due to the higher molecular mobility than in the LC phase. The redox behaviour of the DNA-surfactant complex was also investigated in $\mathrm{CH}_{2} \mathrm{Cl}_{2}$ solution (Supplementary Fig. 4). Reversible anodic oxidation at the potential of $+1.8 \mathrm{~V}$ versus $\mathrm{Ag}^{+} / \mathrm{Ag}$ was detected. Moreover, a pristine surfactant like DOAB did not show any redox properties.

Switchable electrochromic behaviour in the isotropic liquid phase. The DNA-surfactant complex exhibits reversible electrochromic

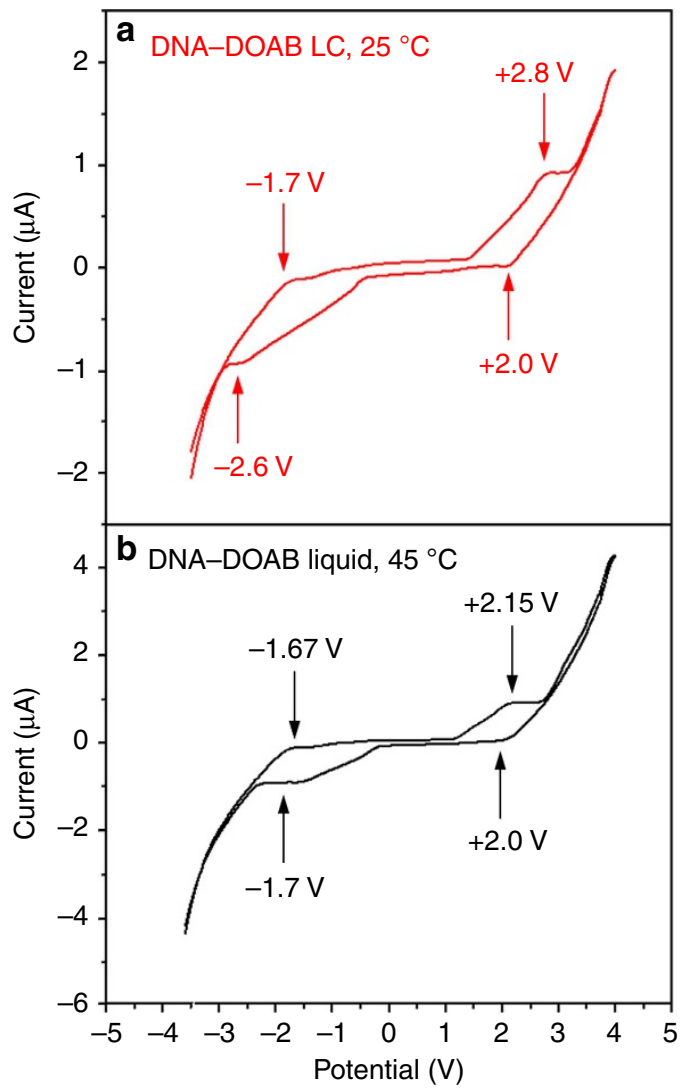

Figure 2 | Bulk cyclic voltammetry spectra of the DNA-surfactant LC material. Here taking 14 mer DNA-DOAB as an example, the DNA-DOAB liquid crystal was filled into a two-ITO-electrode LC cell by capillary force (without reference electrode). In smectic LC phase (a red curve, $25^{\circ} \mathrm{C}$ ), reversible anodic oxidation and cathodic reduction processes of nucleobases were observed at half-wave potentials of +2.4 and $-2.15 \mathrm{~V}$, respectively. In isotropic liquid phase (b black curve, $45^{\circ} \mathrm{C}$ ), similar redox behaviours were observed, but at lower half-wave potentials $(+2.07,-1.68 \mathrm{~V})$.

switching in the isotropic liquid phase in the absence of liquid electrolyte (Fig. 3). A d.c. voltage step from 0 to $4 \mathrm{~V}$ causes the DNA-DOAB material to change colour from clear to magenta at the anode of the cell (Fig. 3a,b). This gave rise to an absorption in the region from 350 to $600 \mathrm{~nm}$ (Fig. 3g). In view of the redox behaviour analysis of the complex, this suggests that DNA in the bulk and solution states undergoes reversible anodic oxidation when a positive potential is applied (Fig. 2 and Supplementary Fig. 4). The oxidized state of DNA in $\mathrm{CH}_{2} \mathrm{Cl}_{2}$ solution also produced an absorption between 350 and $600 \mathrm{~nm}$ (Supplementary Fig. 5). These results are in agreement with oxidation experiments involving radical cations of nucleobases ${ }^{35-39}$ which is accompanied by the same ultraviolet-visible absorption ${ }^{35-37}$. Thus, these observations for the solution phases suggested that the colour change of the DNA-surfactant complex from colourless to magenta (350-600 nm absorption) in the bulk state can be attributed to the formation of nucleobase radical cations at the LC cell anode. The transparent state can then be recovered within several seconds when the voltage across the electrochromic cell is returned to $0 \mathrm{~V}$. Thus, the DNA-DOAB complex exhibits reversible electrochromic properties in the isotropic liquid phase. Control experiments showed that such colour changes did not occur in the pristine surfactant material that lacks a redox-active moiety. Thus, we determine that the solvent-free DNA-surfactant complex can be considered the first example of DNA electrochromism. Previously, DNA has only acted 

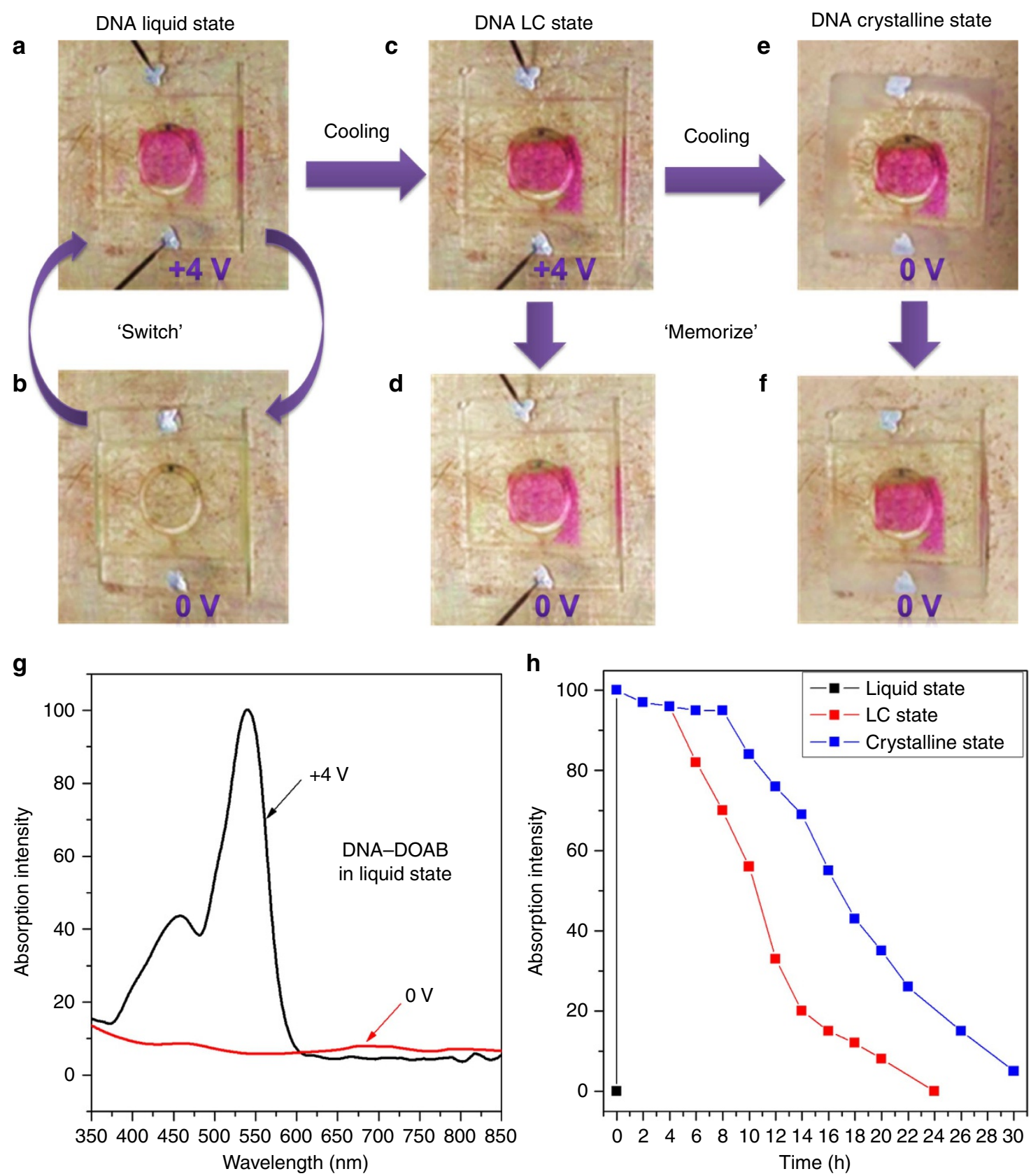

Figure 3 | Phase-dependent electrochromism of DNA-surfactant complex in a LC cell. Here using the 14mer DNA-DOAB complex as a representative example. The ring in the images is a part of the hot stage, which is affixed to the cell by vacuum. (a,b) Switchable electrochromism between the coloured (magenta) and colourless states occurred at the anode in the isotropic liquid phase $\left(45^{\circ} \mathrm{C}\right.$, switch time $\sim 30 \mathrm{~s}$ ). (c) When the coloured DNA-DOAB liquid was cooled to the $\mathrm{LC}$ phase $\left(25^{\circ} \mathrm{C}\right.$, cooling rate $\left.5^{\circ} \mathrm{C} \mathrm{min}^{-1}\right)$ in the presence of applied voltage, the colouration state was preserved. (d) When the bias was removed, remarkable optical memory of the DNA-DOAB smectic LC can be observed as a persistent coloured state. (e) Further cooling the coloured DNA-DOAB LC phase to the crystalline phase $\left(-20^{\circ} \mathrm{C}\right)$ without the application of voltage, (f) the relaxation rate of the coloured state was significantly reduced. ( $\mathbf{g}$ ) Strong absorption bands in the ultraviolet-visible absorption spectrum of the DNA-DOAB liquid $\left(45^{\circ} \mathrm{C}\right.$ ) appeared in the region of 350 to $600 \mathrm{~nm}$ under applied voltage (black curve) and disappear shortly after the voltage was removed. (h) Decay kinetics of the coloured state in different phases (the points were recorded after the applied voltage was returned to $0 \mathrm{~V}$ ). In the isotropic liquid phase, the colour decayed completely within $\sim 30$ s after a removal of bias (black curve). In the smectic LC phase (red curve, corresponding to Fig. 2d), the colour intensity was maintained above $95 \%$ for $4 \mathrm{~h}$ and the colourless state was recovered within $24 \mathrm{~h}$. In the crystalline phase (blue curve, corresponding to Fig. 2e,f), the colour intensity is maintained above $95 \%$ for $\sim 8 \mathrm{~h}$ and complete bleaching was only evident at $30 \mathrm{~h}$.

as an electrolyte or as the host for dispersing electrochromic materials in electrochromic devices ${ }^{40,41}$.

Optical switching rates of the DNA-surfactant complexes in the isotropic phase were examined by applying a double potential step from 0 to $4 \mathrm{~V}$ and back to $0 \mathrm{~V}$. It is found that the electrochromic response time of these materials is correlated with the length of the DNA used (Table 1 and Supplementary Fig. 6), suggesting that the rate of DNA oxidation is limited by the rate of mass transport to the anode. The 6mer DNA-DOAB liquid exhibited response time of about $15 \mathrm{~s}$ in switching between the coloured and colourless states, whereas the $14 \mathrm{mer}, 22 \mathrm{mer}$ and 50 mer had significantly longer response times of 30, 80 and $120 \mathrm{~s}$, 


\section{Table 1 | Switching times of the DNA electrochromics in the} isotropic liquid phase.

\begin{tabular}{lcc} 
DNA length & Switch on & Switch off \\
\hline 6mer DNA & $\sim 15 \mathrm{~s}$ & $\sim 14 \mathrm{~s}$ \\
14 mer DNA & $\sim 30 \mathrm{~s}$ & $\sim 26 \mathrm{~s}$ \\
$22 \mathrm{mer} D N A$ & $\sim 80 \mathrm{~s}$ & $\sim 70 \mathrm{~s}$ \\
50 mer DNA & $\sim 120 \mathrm{~s}$ & $>100 \mathrm{~s}$ \\
\hline
\end{tabular}

Here using the DNA-DOAB complex as a representative example $\left(45^{\circ} \mathrm{C}\right)$. The electrochromic response time of these materials is correlated with the length of the DNA used.

respectively. These results indicate that increasing the dynamic radius of the DNA component leads to a reduction in the rate of DNA diffusion and thus affects the molecular mobility of the chromogenic component. To investigate the electrochromic stability of these DNA-surfactant ionic materials, 30 cycles of colouration and bleaching were carried out in a sequence of double-potential steps (Supplementary Fig. 7a, last seven cycles shown for 6mer DNA-DOAB; Supplementary Fig. 7c, last two cycles shown for 22mer DNA-DOAB). The colour switching remained reversible and switching time of the last cycle did not significantly deviate from that of the first cycle (Supplementary Fig. 6). Homogeneous focal-conic textures were recovered after cooling the electrochemically cycled samples to the LC phase (Supplementary Fig. 7b,d), indicating that the ionic DNA-surfactant complexes are stable within this time frame.

Optical memory behaviours in the LC and crystalline phases. When the DNA-surfactant liquid was cooled to the smectic LC phase while an applied voltage of $4 \mathrm{~V}$ was maintained, the magenta colour was conserved (Fig. 3c). Even after the cell voltage was returned to $0 \mathrm{~V}$, the colouration state was temporally preserved in the smectic LC phase (Fig. 3d) and completely bleached within $24 \mathrm{~h}$ (Fig. $3 \mathrm{~h}$, red curve and Supplementary Fig. 8). Further cooling the DNA-DOAB material in the magenta colour state from the $\mathrm{LC}$ to the crystalline phase in the absence of applied voltage (Fig. 3e,f) extended the persistence time of the magenta state (Fig. 3h, blue curve and Supplementary Fig. 9). The complete recovery of the colourless state in the crystalline phase was observed within about $30 \mathrm{~h}$. In addition, the coloured DNA-DOAB was bleached immediately after extracting the material from the cell by ethanol (Supplementary Fig. 10). This suggests that the radical cations are reduced quickly in solution. These results clearly indicated that the radical cations of nucleobases can be stabilized in the solvent-free and structured DNA-surfactant materials. Thus, a method to modulate the volatility of the optical memory was developed by controlling the phase of the DNA-surfactant complex.

POM was used to investigate the birefringence textures and they relate to the activated colour domains. In the isotropic liquid and smectic LC phases with an applied voltage of $4 \mathrm{~V}$, a homogenous formation of red colour was observed in the device (Fig. 4 and Supplementary Fig. 11). It is found that the focal-conic textures became much smaller or disappeared in the coloured DNA-DOAB domains in comparison with the uncoloured DNA-DOAB birefringence domains without ITO coating (Fig. 4). We assume that reorientation of the oxidized DNA-DOAB smectic layers took place due to the applied voltage during the transition process from the isotropic to the LC phase (Fig. 3, from a to c). In the presence of an applied voltage, the capacitive positive charge at the anode may attract the negatively charged DNA, favouring a horizontal alignment of the nucleic acid layers in relation to the anode surface. When the applied voltage was switched to $0 \mathrm{~V}$, the coloured DNA with

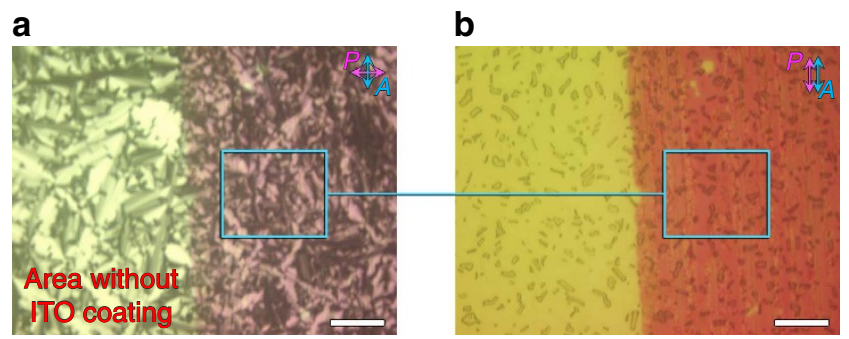

Figure 4 | The study of electrochromic behaviours under microscopy. Investigation of birefringence textures, orientation and colour domains when the DNA-surfactant liquid was cooled to the smectic LC phase while an applied voltage of $4 \mathrm{~V}$ was maintained (here 14 mer DNA-DOAB complex as a representative example). The image of the coloured DNADOAB textures obtained with crossed polarizer and analyzer (a) and the corresponding image (b) where the polarizer and analyzer were parallel. Note that the left part of the images represents areas of the cell without conducting ITO coating, whereas the right parts shows the conductive ITO electrode. The DNA-DOAB formed a homogenous coloured film. The focalconic textures became much smaller or disappeared in the coloured DNA$D O A B$ domains when compared with the uncoloured birefringence

domains. Besides a largely perpendicular lamellar orientation (DNA-DOAB layers oriented vertical to electrode surface), reorientation of the oxidized DNA smectic layers took place, adopting a new type of horizontal alignment (DNA-DOAB layers oriented parallel to electrode surface). Scale bar, $100 \mu \mathrm{m}$.

perpendicular lamellar orientation was bleached (Fig. 5). However, the horizontally aligned DNA-surfactant layers preserved the colouration state. This reorientation effect (compare Figs 1d and 5d) became more apparent after many cycles of applying a positive potential in the isotropic state, cooling to the LC state, removing the potential and again heating to the isotropic state (Fig. 5c,d). The coloured DNA-DOAB smectic layers oriented parallel to the electrode surface, whereas the bleached DNA-DOAB layers remained vertical to the electrode surface. Furthermore, the alignment of the DNA-DOAB lamellar layers was maintained after the colour decays completely (Supplementary Fig. 12a-c). The perpendicular orientation of the bleached DNA-DOAB smectic layers was recovered after an annealing treatment without application of voltage (Supplementary Fig. 12d), confirming the integrity of the ionic DNA-DOAB complexes. Further cooling of the coloured LC sample to the crystalline phase preserved the reorientation of oxidized DNA-DOAB smectic layers (Supplementary Figs 13 and 14). The above results suggest that the reorientation of the oxidized DNA-DOAB smectic layers played an important role in trapping and protecting the coloured radical cations and thus, in achieving the storage characteristics of optical information in the LC and crystalline states.

During a control experiment, when a potential of $4 \mathrm{~V}$ was applied directly to the DNA-DOAB material in the LC phase at $25^{\circ} \mathrm{C}$, the colour impression appeared much slower and with lower intensity than in the isotropic liquid phase (Supplementary Fig. 15). This can be attributed to the lower mobility of DNA molecules in the smectic LC phase. In contrast to the colouration attained in the isotropic phase before transition to the LC phase, the colouration attained in the LC phase decayed completely within $3 \mathrm{~h}$ (Supplementary Fig. 15), indicating that the relaxation time of DNA radical cations was significantly shorter than in the coloured LC sample annealed from the isotropic phase (Fig. 3d,h, red curve). Interestingly, POM analysis did not reveal a difference in the alignments of coloured and uncoloured DNA-DOAB domains, as both exhibited perpendicular orientation of the smectic layers on the ITO surface (Fig. 6). 
a
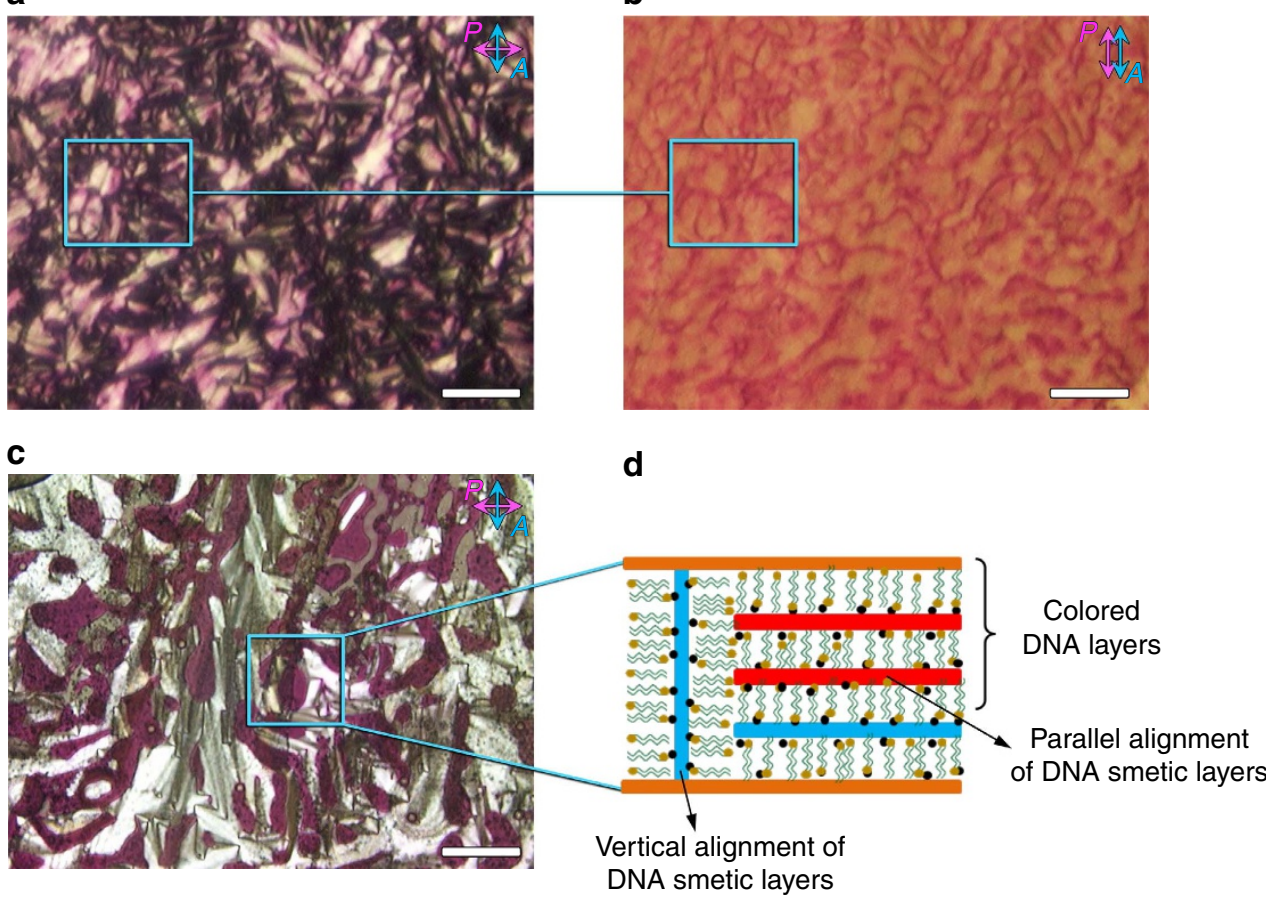

Figure 5 | The study of electrochromic behaviours under microscopy. Investigation of birefringence textures, orientation and colour domains of the coloured DNA-surfactant complex in the LC state $\left(25^{\circ} \mathrm{C}\right)$ in the absence of an applied voltage (corresponding to Fig. 2d, 14mer DNA-DOAB with almost no colour decay within $4 \mathrm{~h}$ ). The image of the coloured DNA-DOAB textures obtained with crossed polarizer and analyzer (a) and the corresponding image (b) where the polarizer and analyzer were parallel. The coloured DNA within normal perpendicular lamellar orientation was bleached, whereas the horizontal alignment of DNA-surfactant layers preserved the colouration state. (c) This reorientation effect became more apparent after 10 cycles of applying a positive potential in the isotropic state, cooling to the LC state, removing the potential and again heating to the isotropic state. The coloured DNA-DOAB smectic layers oriented parallel to the electrode surface, whereas the bleached DNA-DOAB layers remained vertical to the electrode surface. (d) The corresponding sketch of the lamellar alignment of the coloured and the bleached DNA-DOAB domains. Scale bar, $50 \mu \mathrm{m}$.

Mechanism for phase-dependent DNA electrochromism. As depicted in Fig. 7a,b, in the isotropic phase, mobile segments of oligonucleotide are oxidized at the anodic electrode when a positive potential of $4 \mathrm{~V}$ is applied. The accumulation of radical cations manifests as the magenta coloured state. When a potential of $0 \mathrm{~V}$ is applied, the DNA radical cations are reduced, which leads to rapid bleaching in the liquid state. When the coloured DNA-surfactant liquid is cooled while a positive potential of $4 \mathrm{~V}$ is applied, the magenta DNA-surfactant complexes develop a lamellar LC structure with parallel alignment to the electrode surfaces besides the normal perpendicular lamellar orientation (Fig. 7c). When the electric field is switched off, the coloured DNA with perpendicular lamellar orientation is bleached (Fig. 7d). This is probably due to the efficient electron transfer through vertical nucleobase sublayers. However, in the horizontal alignment of the oxidized DNA-surfactant complex, the surfactant sublayers may act as insulating barrier and prevent electron hopping. Therefore, the reduction process of DNA radical cations might be slowed down and the generated colouration state could be preserved long time (Fig. $7 \mathrm{~d}$ ). It should be also noted that the oxidized DNA molecules diffuse further away from the anode surface in the isotropic phase than in the LC state. Therefore, in cooled samples from the isotropic melts, the DNA radical cations are trapped and the coloured state requires a longer time to relax back to the colourless state compared with samples that are directly oxidized in the LC state. Owing to the mechanisms discussed above, the response of a coloured state of DNA-surfactant material can be controlled via a simple phase transition strategy in the absence of applied voltage.
Tunability of optical memory performance. To further illustrate the importance of material phases (isotropic liquid-LC-crystal) for tuning durability of stored optical information, a series of DNA-surfactant complexes with phase transition temperatures that range from -20 to $130{ }^{\circ} \mathrm{C}$ have been prepared (Supplementary Fig. 3). It can be seen that the magenta colour of the DNA-DOAB liquid decays within $30 \mathrm{~s}$ after removing the potential at $45^{\circ} \mathrm{C}$ (Fig. 8a, black curve and Supplementary Fig. 6b). At the same temperature, DNA-0.5DOAB-0.5DEAB adopted the smectic LC phase and the colour impression, after activation in the isotropic state, is decaying within $\sim 10 \mathrm{~h}$ (Fig. 8a, red curve and Supplementary Fig. 16). This indicates that the lamellar layers of the DNA-surfactant complex can trap and stabilize the radical cations much more efficiently than the disordered liquid phase. At $25^{\circ} \mathrm{C}$, the DNA-DOAB smectic LC exhibited an extended optical memory, showing full colour decay within $\sim 24 \mathrm{~h}$ after removal of applied potential (Fig. 8a, blue curve and Supplementary Fig. 8). The crystalline state of the DNA-DEAB at this temperature showed a longer memory time of $\sim 28 \mathrm{~h}$ until full bleaching occurred (Fig. 8a, green curve and Supplementary Fig. 17). We attribute the differences in the rates of colour formation and decay among the different phases and surfactant compositions to differences in the ionic mobility of the coloured DNA component. We have previously reported that the viscosity of the DNA-surfactant complex, which was inversely proportional to ionic mobility, increased with the increasing surfactant alkyl chain length ${ }^{34}$. It is thus reasonable that the rate of decay of the magenta colour impression correlated inversely with LC viscosity (Fig. 8b and Supplementary Figs 18 and 19). 


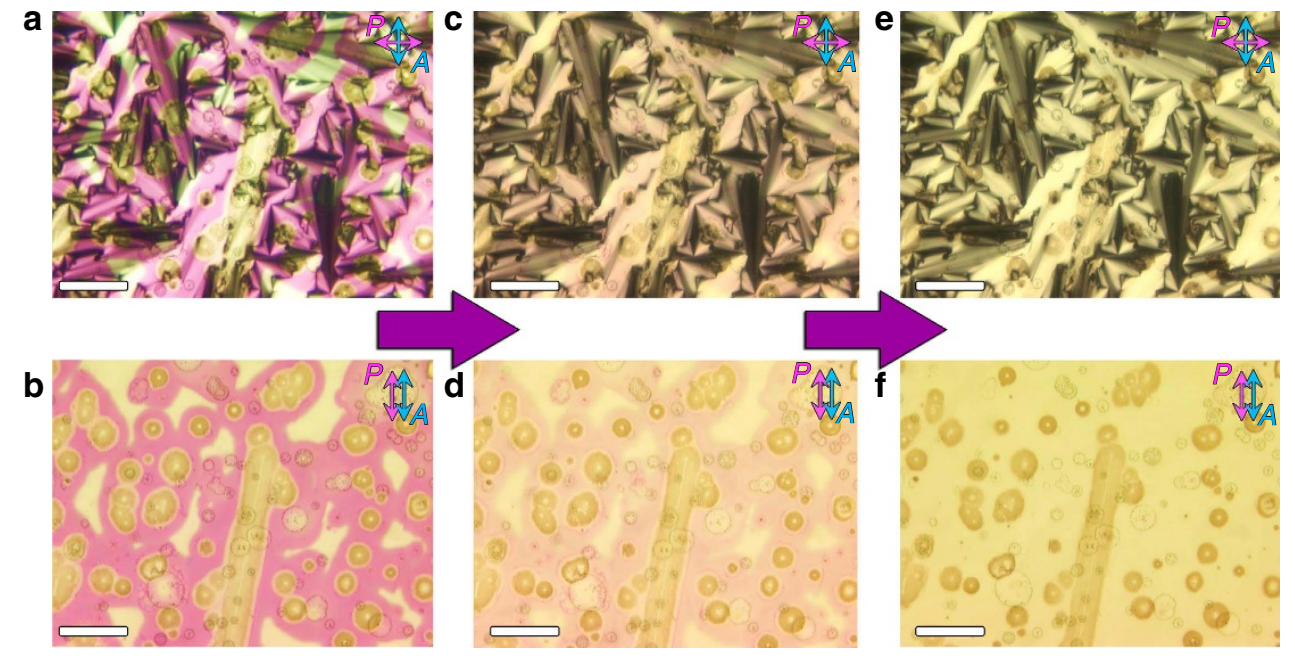

Figure 6 | The study of electrochromic behaviours under microscopy. Investigation of birefringence textures, orientation, colour domains and colour decay after the application of $4 \mathrm{~V}$ directly to a DNA-DOAB complex in the LC phase (scale bar, $100 \mu \mathrm{m}$ ). The optical images between crossed polarizer and analyzer ( $\mathbf{a}, 0 \mathrm{~h} ; \mathbf{c}, 2 \mathrm{~h} ; \mathbf{e}, 4 \mathrm{~h}$ ) and the corresponding images with parallel polarizer and analyzer $(\mathbf{b}, 0 \mathrm{~h} ; \mathbf{d}, 2 \mathrm{~h} ; \mathbf{f}, 4 \mathrm{~h})$ showed that the birefringence domains of coloured DNA-DOAB smectic layers remained unaltered, exhibiting perpendicular lamellar orientation. The colourless state was recovered in $\sim 3 \mathrm{~h}$, which was a significantly shorter recovery time than when the coloured LC state was obtained from the isotropic phase.
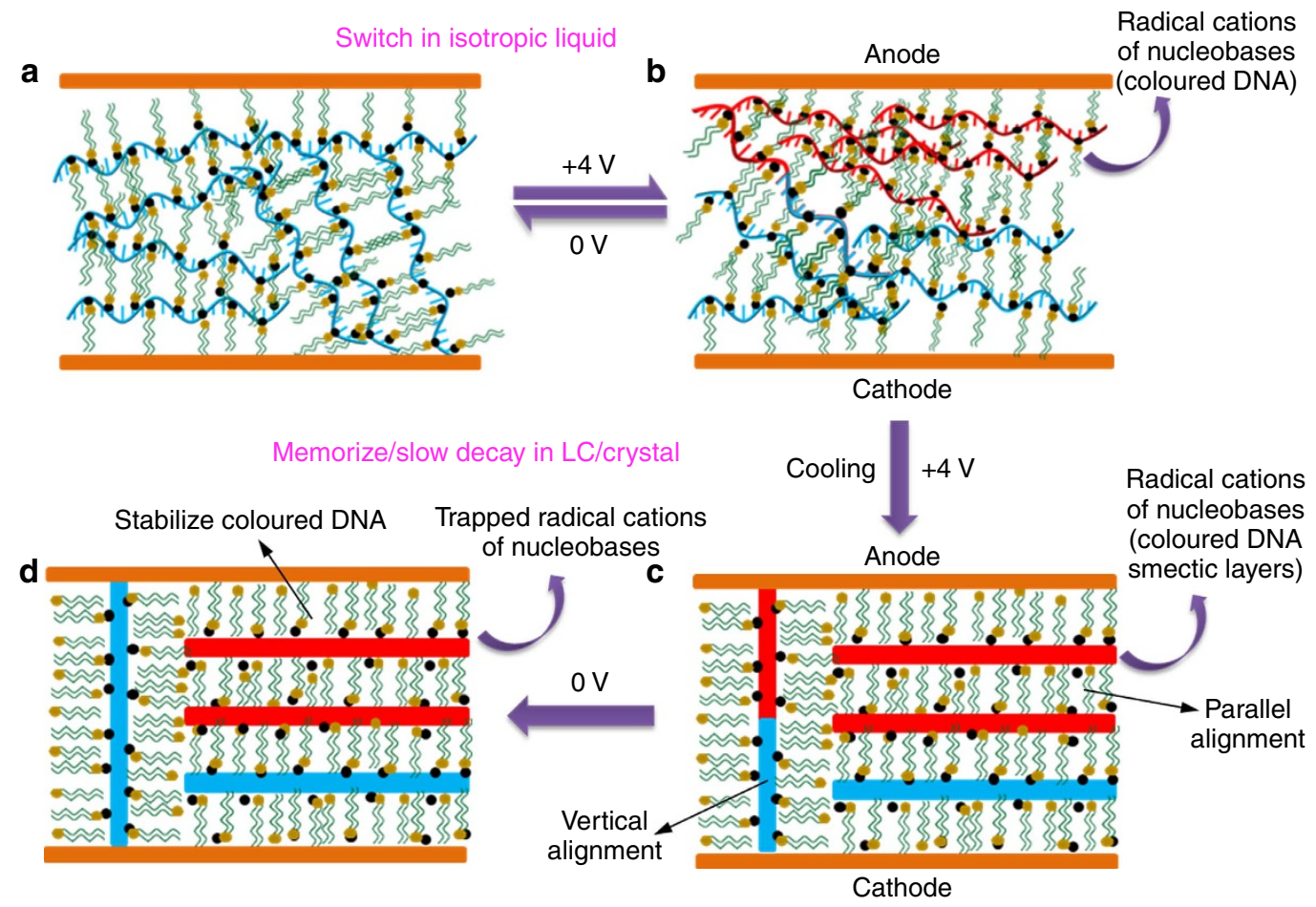

Figure 7 | Electrochromic mechanism of the DNA-surfactant complexes. (a) The fluid DNA-surfactant material in their isotropic liquid phase.

(b) Upon applying an electric field, reversible anodic oxidation and cathodic reduction processes of nucleobases take place. Radical cations are produced on the anodic electrode surface, resulting in the colouration of the DNA-surfactant materials. Once a potential of $0 \mathrm{~V}$ is applied, the radical cations are reduced and the bleaching process takes place. Thus, switchable electrochromic response is observed in the isotropic liquid phase. (c) When the complex is cooled to the smectic LC or crystalline phases under applied voltage, the coloured DNA-surfactant complexes develop a horizontal lamellar alignment besides the normal perpendicular lamellar orientation. (d) When the applied voltage is returned to $0 \mathrm{~V}$, the coloured DNA within perpendicular lamellar orientation is bleached. The horizontal alignment of DNA-surfactant layers preserved the colouration state, which is responsible for trapping and protecting the coloured radical cations and thus, in achieving the optical storage characteristics in the LC and crystalline states.

DNA-LC optical memory device for smart tag application. Two important features of the electrochromic behaviour of DNA-surfactant complexes have been demonstrated above. (1) The decay time of the coloured state in the isotropic melt is in the range of seconds depending slightly on the length of the DNA molecule. (2) The decay in the LC state occurs within several hours and can be tuned by the selection of the surfactant complexed with DNA. These intriguing material characteristics can be combined and exploited for the fabrication of smart tags that exhibit a clock function and a ceiling temperature indicator. 
a

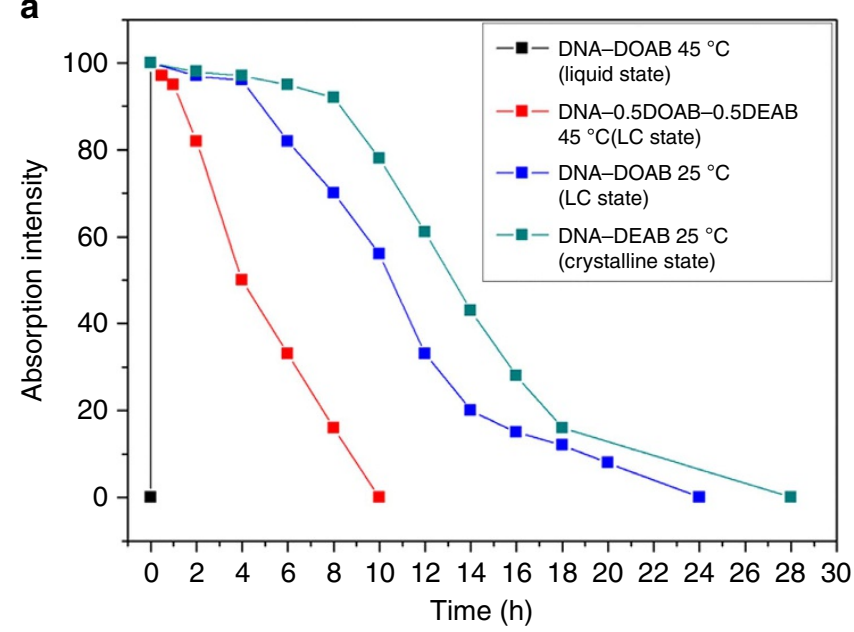

b

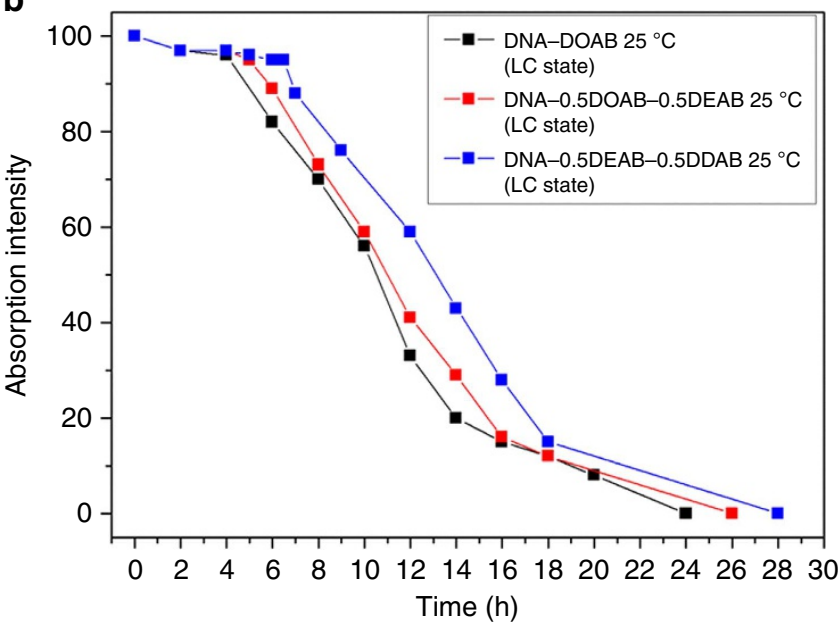

Figure 8 | Colour decay kinetics of the DNA-surfactant samples. The materials are complexed with different surfactants, surfactant mixtures and 14 mer DNA. (a) Phase-dependent memory behaviour of the materials. The magenta colour of DNA-DOAB isotropic liquid was bleached in $30 \mathrm{~s}$ at $45^{\circ} \mathrm{C}$ after removal of bias (black curve). At the same temperature, the colour impression of the DNA-0.5DOAB-0.5DEAB smectic LC phase was preserved almost completely for $\sim 1 \mathrm{~h}$ after the removal of the bias (black curve). At $25^{\circ} \mathrm{C}$, the DNA-DOAB smectic LC exhibited enhanced optical memory with negligible colour decay within $\sim 4 \mathrm{~h}$ (blue curve). The crystalline state of the DNA-DEAB at this temperature showed a much longer relaxation time of $\sim 7.5 \mathrm{~h}$ (green curve). (b) Viscosity-dependent memory behaviours of the materials. The magenta colour impression of the DNA-surfactant smectic $L C s\left(25^{\circ} \mathrm{C}\right)$ was extended from $\sim 4 \mathrm{~h}$ (DNA-DOAB, black curve) to $\sim 5.5 \mathrm{~h}$ (DNA-0.5DOAB-0.5DEAB, red curve) and further to $\sim 7 \mathrm{~h}$ (DNA-0.5DEAB-0.5DDAB, blue curve) with increasing the alkyl chain lengths of the surfactants.

For demonstration of this dual functionality, we have chosen the $14 \mathrm{mer}$ DNA-DOAB complex as an example. After activation of the tag in the isotropic melt, cooling and removal of voltage, the coloured state decayed slowly at room temperature. However, when the temperature was raised to $55^{\circ} \mathrm{C}$, after $2 \mathrm{~h}$, the magenta colour disappeared within $60 \mathrm{~s}$ (Fig. 9a, black curve and Fig. 9b; Supplementary Fig. 20). Similar, a sample with $\sim 50 \%$ colour decay after $10 \mathrm{~h}$ was bleached within $45 \mathrm{~s}$ when the temperature was adjusted to $55^{\circ} \mathrm{C}$ (Fig. 9a, red curve; and Supplementary Fig. 21). Taking into account that the isotropic liquid-LC transition in the DNA-surfactant materials can be conveniently tuned in the wide range between 130 and $41{ }^{\circ} \mathrm{C}$ (Supplementary Fig. 3), a series of smart tags with different decay behaviours and ceiling temperatures can be fabricated. This is illustrated in Fig. 9c (Supplementary Fig. 22) and Fig. 9d (Supplementary Fig. 23) for DNA-0.3DOAB-0.7DEAB and DNA-0.3DEAB-0.7DDAB, respectively. Although for the former material an instantaneous colour decay is observed at already $80^{\circ} \mathrm{C}$, the latter DNA-surfactant complex requires a temperature of $125^{\circ} \mathrm{C}$ for bleaching in seconds. One can imagine that these behaviours of DNA-surfactant LCs offer great opportunities for developing smart tag applications, especially with respect to packed perishable product inspection. We equipped a food package with an activated DNA-LC device and demonstrated functionality as combined time and temperature indicator (Supplementary Fig. 24).

\section{Discussion}

A new type of electrochromic material based on redox-active nucleic acids has been developed by mixing DNA and cationic surfactant. Phase-dependent electrochromism is an inherent characteristic of the DNA-surfactant complex, where fluidity and ordering are introduced by ionic self-assembly ${ }^{42-44}$. The rate of colour decay was modulated very broadly, simply by controlling the phase of the material. In the isotropic liquid phase, the DNA-surfactant complex exhibits stable, reversible switching between the colourless and magenta states. In stark contrast to conventional LC electrochromic devices ${ }^{7,24-26}$, the colouration state can be maintained over an extended period of time in the smectic LC phase or the crystalline phase without applying voltage. The time required for complete decay can range from a few seconds to over a day, which provides for a simple and effective way to modulate the volatility of stored optical information. This new type of DNA materials can be easily processed to fabricate single-layer electrochromic devices without the need for external electrolyte layers. To the best of our knowledge, the approach to controlling the volatility of stored optoelectronic information by modulating the phase of the material has never previously been proposed or attempted. Due to the broad and stable phases, these DNA-surfactant materials hold great promise for the realization of novel types of smart tags or optical devices as well as for diagnostic devices where recognition or biocatalytic events lead to phase transitions.

\section{Methods}

Materials. The surfactants used for the DNA complex formation, including $\mathrm{DOAB}$ and DDAB were purchased from ABCR (Germany), and DEAB was aquired from Sigma Aldrich. Single-stranded DNA, including 6mer (5'-CCT CGC-3', molecular weight $\left.(\mathrm{MW})=1,728 \mathrm{~g} \mathrm{~mol}^{-1}\right), 14 \mathrm{mer}\left(5^{\prime}\right.$-CCTCGCTCTGC TAA-3', MW $=4,175 \mathrm{~g} \mathrm{~mol}^{-1}$ ) and 22mer ( $5^{\prime}$-CCTCGCTCTGCTAATCCTG TTA-3', MW $=6,612 \mathrm{~g} \mathrm{~mol}^{-1}$ ) were synthesized by conventional solid-phase synthesis method ${ }^{45}$. The 50mer DNA strand (5'-CCTCGCTCTGCTAATCCTGT TACCTCGCTCTGCTAATCCTGTTACCTCGC-3', MW $=15,077 \mathrm{~g} \mathrm{~mol}^{-1}$ ) was purchased from BIOMERS (Germany). Tetrabutylammonium perchlorate $\left(\mathrm{Bu}_{4} \mathrm{NClO}_{4}, \mathrm{Mw}=341.91 \mathrm{~g} \mathrm{~mol}^{-1}\right)$, used as the supporting electrolyte for cyclic voltammetry measurements was purchased from Sigma.

DNA-surfactant complex preparation. The single-stranded DNA (6mer, 14mer, 22 mer and 50mer) was pretreated by precipitating a $\sim 300 \mu \mathrm{M}$ DNA solution containing $5 \mathrm{M} \mathrm{NaCl}$ with cold ethanol $\left(-20^{\circ} \mathrm{C}\right)$. From this precipitate, an aqueous DNA solution $(\sim 300 \mu \mathrm{M})$ was prepared in ultrapure water. In a second solution made from ultrapure water, the concentration of single surfactant (DOAB, DEAB and DDAB) or a two-surfactant mixture (DOAB:DEAB, DOAB:DDAB and DEAB:DDAB, molar ratios 7:3, 5:5 and 3:7) were adjusted to $5-10 \mathrm{mM}$ at room temperature. Both the DNA and surfactant solutions $(\sim 5 \mathrm{~mol}$ equivalents of surfactant relative to nucleotides of the DNA) were mixed together and as a result the insoluble complexes precipitated from the aqueous phase. After centrifugation, the water and unreacted surfactants were removed, and finally the complexes were lyophilized overnight before further characterization. 
a

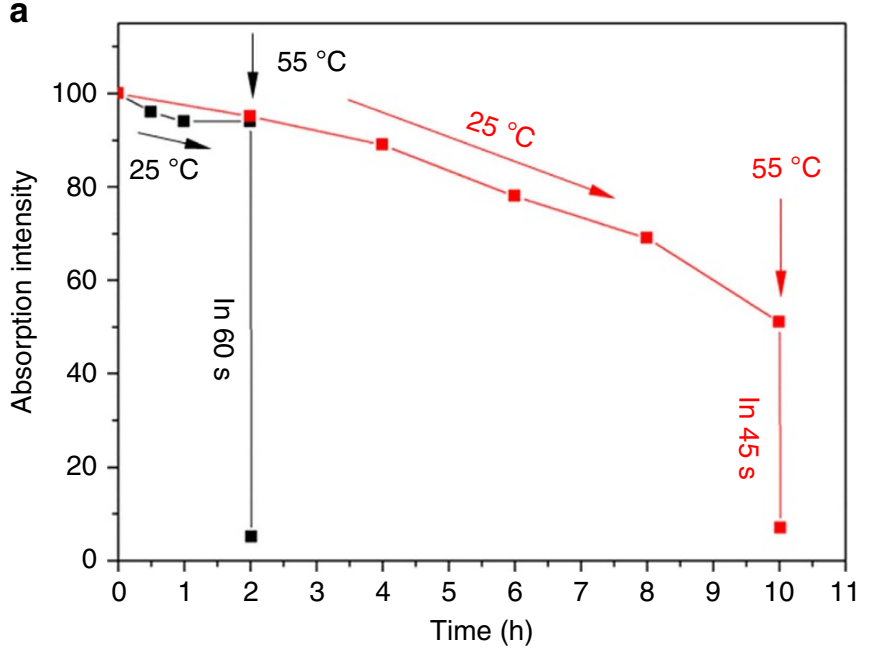

b

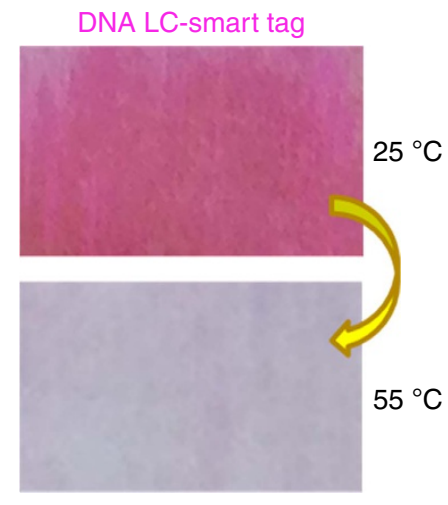

c

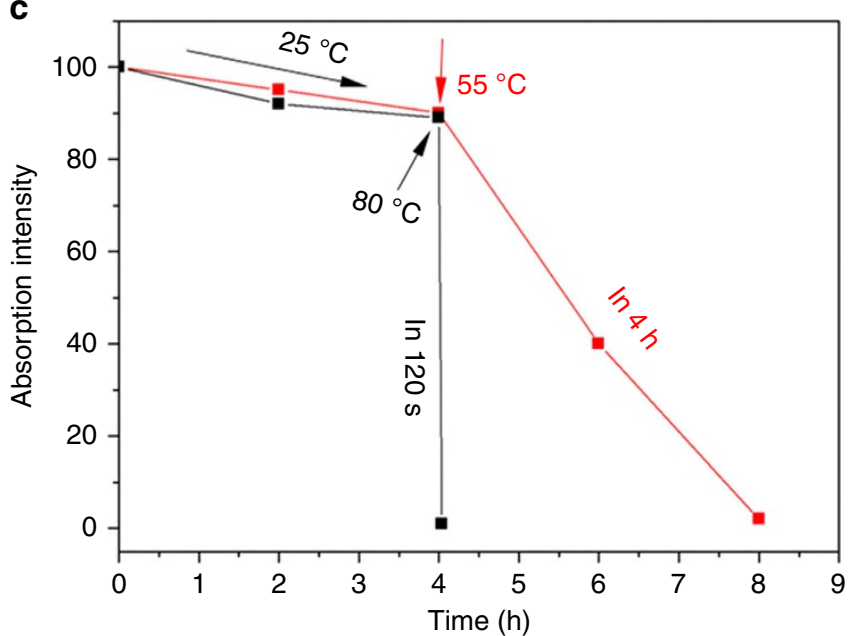

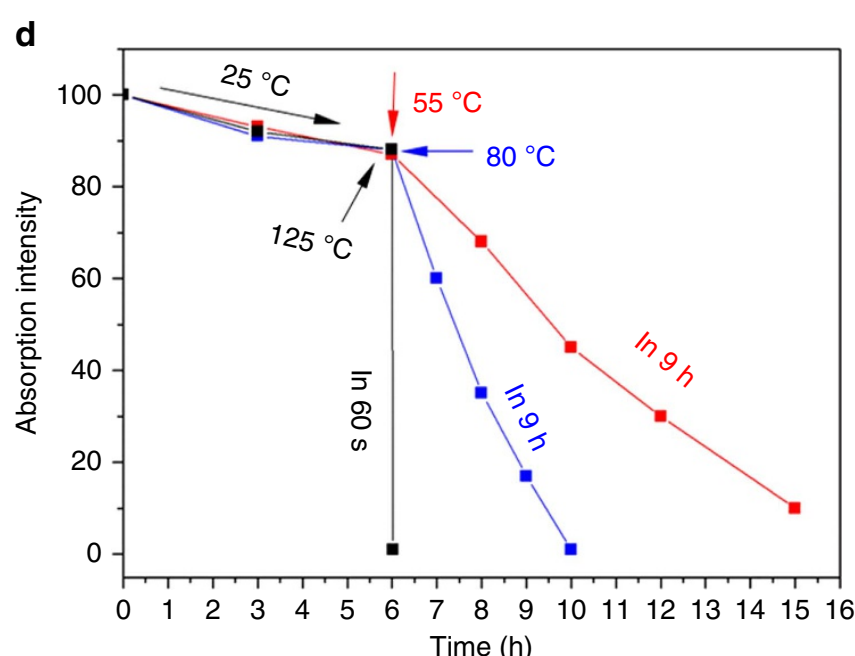

Figure 9 | Decay kinetics of the coloured DNA-surfactant samples. (a) At $25^{\circ} \mathrm{C}$, the color-activated 14 mer DNA-DOAB LC sample showed a very slow colour decay in the absence of applied voltage. Once the sample was heated to $55^{\circ} \mathrm{C}$ (for example, after 2 or $10 \mathrm{~h}$ after activation of the memory device), the colour decayed completely within $60 \mathrm{~s}$. (b) The corresponding photographs of the coloured $\left(25^{\circ} \mathrm{C}\right)$ and bleached $\left(55^{\circ} \mathrm{C}\right)$ samples. $(\mathbf{c})$ For activated 14 mer DNA-0.3DOAB-0.7DEAB at $55^{\circ} \mathrm{C}$, the bleaching process is significantly slowed down, whereas at $80^{\circ} \mathrm{C}$ the colour decay is realized within 2 min. (d) For activated $14 \mathrm{mer}$ DNA-0.3DEAB-0.7DDAB, a temperature increase to 55 and $80^{\circ} \mathrm{C}$ yields only a slow colour decay, but above a temperature of $125^{\circ} \mathrm{C}$, bleaching occurs within a minute.

Electrochromic device fabrication. The prepared DNA-surfactant complexes were filled into a commercial liquid crystal cell consisting of two ITO-coated glass plates (LC4-6.8, ITO area $5 \mathrm{~mm} \times 5 \mathrm{~mm}$, gap $6.8 \mu \mathrm{m}$, INSTEC, USA). There are two openings on the cell. A small amount of the DNA-surfactant sample was placed over one opening, which lead to capillary forces pulling the liquid crystal material into the empty cell. This process can be accelerated by heating the materials to the isotropic states.

Electrochromic measurement. The DNA-surfactant complex was introduced into the electrochemical cell and heated to the isotropic phase. The potential was then switched between 4 and $0 \mathrm{~V}$ over the course of the switching response studies. Subsequently, the complex was cooled to the smectic LC phase (cooling rate $5^{\circ} \mathrm{C}$ min $^{-1}$ ) under an applied potential of $4 \mathrm{~V}$. After cooling, the electric field was switched off to study the relaxation time of the coloured state. In other experiments, the coloured LC state was immediately cooled to the polycrystalline phase (cooling rate $5^{\circ} \mathrm{Cmin}^{-1}$ ) in the absence of an applied electric field.

Characterization of DNA-surfactant liquid crystals. Thermal behaviours of the DNA-surfactant complexes were investigated by differential scanning calorimetry using a TA Instruments Q1000 system in a nitrogen atmosphere with a heating/ cooling rate of $5^{\circ} \mathrm{C} \mathrm{min}-1$. The structural features of the DNA-surfactant complexes were analysed by wide-angle X-ray scattering (WAXS). WAXS with heating and cooling systems was carried out by a custom, rotating-anode-based setup $^{46}$, made in-house, where the sample-to-detector distance was $13 \mathrm{~cm}$ and a conventional X-ray source with radiation wavelength of $\lambda=1.54 \AA$ was used.
Smectic layer structures of the DNA-surfactant complexes were carried out by freeze-fractured transmission electron microscopy (FF-TEM) according to a standard protocoll ${ }^{47}$. FF-TEM was performed by sandwiching the samples between $2 \mathrm{~mm}$ by $3 \mathrm{~mm}$ glass planchettes and cooling from the isotropic melt to a selected temperature in the LC range. The samples were then rapidly quenched to $\mathrm{T}<-180^{\circ} \mathrm{C}$ by immersion in liquid propane, fractured in vacuum at $-140^{\circ} \mathrm{C}$ and then coated with $2 \mathrm{~nm}$ of platinum and then with $25 \mathrm{~nm}$ of carbon. After dissolving the liquid crystal, the $\mathrm{Pt}-\mathrm{C}$ replicas were placed in the TEM, where the topographic structure of the fracture plane was observed. Textures and orientation analysis of the complexes were studied by POM. POM was conducted on a Zeiss Axiophot using the same temperature program that was used for the differential scanning calorimetry experiments. Electrochemical behaviours of the DNA-surfactant complexes were investigated in the solution and in the bulk material. Standard cyclic voltammetry (CV) in solution was performed in a three-electrode cell equipped with a Pt working electrode,

a Pt counter electrode and an $\mathrm{Ag}^{+} / \mathrm{Ag}$ reference electrode. A solution of $\mathrm{Bu}_{4} \mathrm{NClO}_{4}$ in $\mathrm{CH}_{2} \mathrm{Cl}_{2}(0.10 \mathrm{M})$ was used as the supporting electrolyte. The sweep rate is $100 \mathrm{mV} \mathrm{s}^{-1}$. The electrical spectrum in the bulk (in the electrochromic cell described above) was measured by a semiconductor parameter analyzer (4155B, Hewlett packard). Electrochromic behaviours were examined on a hot stage (heating/cooling rate of $5{ }^{\circ} \mathrm{C} \mathrm{min}^{-1}$ ) with d.c. voltage control. Ultraviolet-visible absorption spectra were recorded with a JASCO V-630 spectrophotometer for the study of the reversible electrochromism and optical memory (decay kinetics) properties. Electrochromic switching time between colouration and bleaching of the DNA-surfactant complexes in the isotropic liquid phases were measured and analysed by processing the recorded videos with the ImageJ software (National Institutes of Health). 


\section{References}

1. Beaujuge, P. M. \& Reynolds, J. R. Color control in pi-conjugated organic polymers for use in electrochromic devices. Chem. Rev. 110, 268-320 (2010).

2. Mortimer, R. J. Electrochromic materials. Chem. Soc. Rev. 26, 147-156 (1997).

3. Rosseinsky, D. R. \& Mortimer, R. J. Electrochromic systems and the prospects for devices. Adv. Mater. 13, 783-793 (2001).

4. Monk, P. M. S., Mortimer, R. J. \& Rosseinsky, D. R. Electrochromism and electrochromic Devices (Cambridge Univ. Press, 2007).

5. Bird, C. L. \& Kühn, A. T. Electrochemistry of the viologens. Chem. Soc. Rev. 10, 49-82 (1981).

6. Schoot, C. J., Ponjee, J. J., van Dam, H. T., van Doorn, R. A. \& Bolwijn, P. T. New electrochromic memory display. Appl. Phys. Lett. 23, 64-65 (1973).

7. Yamamura, K., Okada, Y., Kominami, S. O. K. \& Tabushi, I. New liquid crystalline viologens exhibiting electric stimulus-response behavior. Tetrahedron Lett. 28, 6475-6478 (1987).

8. Tanabe, K., Yasuda, T., Yoshio, M. \& Kato, T. Viologen-based redox-active ionic liquid crystals forming columnar phases. Org. Lett. 9, 4271-4274 (2007).

9. Sanehira, Y., Uchida, S., Kubo, T. \& Segawa, H. A distinguished retentive memory using polyethylene glycol electrolyte solvent for viologen modified titania electrochromic device. Electrochemistry 76, 150-153 (2008).

10. Lu, W. et al. Use of ionic liquids for conjugated polymer electrochemical devices. Science 297, 983-987 (2002).

11. Jensen, J., Dyer, A. L., Shen, D. E., Krebs, F. C. \& Reynold, J. R. Direct photopatterning of electrochromic polymers. Adv. Funct. Mater. 23, 3728-3737 (2013).

12. Alamer, F. A., Otley, M. T., Ding, Y. \& Sotzing, G. A. Solid-state high-throughput screening for color tuning of electrochromic polymers. Adv. Mater. 25, 6256-6260 (2013).

13. Yen, H., Chen, C. \& Liou., G. Flexible multi-colored electrochromic and volatile polymer Memory devices derived from starburst triarylamine-based electroactive polyimide. Adv. Funct. Mater. 23, 5307-5316 (2013).

14. de Tacconi, N. R., Rajeshwar, K. \& Lezna, R. O. Metal hexacyanoferrates: electrosynthesis, in situ characterization, and applications. Chem. Mater. 15, 3046-3062 (2003).

15. Wade, C. R., Li, M. \& Dincă, M. Facile deposition of multicolored electrochromic metal-organic framework thin films. Angew. Chem. Int. Ed. 52, 13377-13381 (2013)

16. Han, F. S., Higuchi, M. \& Kurth, D. G. Metallo-supramolecular polymers based on functionalized bis-terpyridines as novel electrochromic materials. $A d v$. Mater. 19, 3928-3931 (2007).

17. Kurth, D. G., López, J. P. \& Dong, W. F. A new Co(II)-metalloviologen-based electrochromic material integrated in thin multilayer films. Chem. Commun. 2119-2121 (2005).

18. Deb, S. K. A novel electrophotographic system. Appl. Opt. 3, 192-195 (1969).

19. Zhang, Y., Lee, S. H., Mascarenhas, A. \& Deb, S. K. An UV photochromic memory effect in proton-based $\mathrm{WO}_{3}$ electrochromic devices. Appl. Phys. Lett. 93, 203508 (2008).

20. Liu, S., Kurth, D. G., Möhwald, H. \& Volkmer, D. A thin-film electrochromic device based on a polyoxometalate cluster. Adv. Mater. 14, 225-228 (2002).

21. Liu, J. et al. Ultrathin $\mathrm{W}_{18} \mathrm{O}_{49}$ nanowire assemblies for electrochromic devices. Nano Lett. 13, 3589-3593 (2013).

22. Goodby, J. W. et al. in Handbook of Liquid Crystals 2nd edn (eds Goodby, J. W., Collings, P. J., Kato, T., Tschierske, C., Gleeson, H. \& Raynes, P.) (2014).

23. Clark, N. A. \& Lagerwall, S. T. Submicrosecond bistable electro-optic switching in liquid crystals. Appl. Phys. Lett. 36, 899-901 (1980).

24. Yazaki, S., Funahashi, T. \& Kato, M. An electrochromic nanostructured liquid crystal consisting of $\pi$-conjugated and ionic moieties. J. Am. Chem. Soc. 130, 13206-13207 (2008)

25. Yazaki, S., Funahashi, M., Kagimoto, J., Ohno, H. \& Kato, T. Nanostructured liquid crystals combining ionic and electronic functions. J. Am. Chem. Soc. 132, 7702-7708 (2010).

26. Beneduci, A., Cospito, S., La Deda, M., Veltri, L. \& Chidichimo, G. Electrofluorochromism in $\pi$-conjugated ionic liquid crystals. Nat. Commun 5, 3105 (2014).

27. Kelley, S. O. \& Barton, J. K. Electron transfer between bases in double helical DNA. Science 283, 375-381 (1999).

28. Slinker, J. D., Muren, N. B., Renfrew, S. E. \& Barton, J. K. DNA charge transport over $34 \mathrm{~nm}$. Nat. Chem. 3, 228-233 (2011).

29. Bruot, C., Palma, J. L., Xiang, L., Mujica, V., Ratner, M. A. \& Tao, N. Piezoresistivity in single DNA molecules. Nat. Commun. 6, 8032 (2015).

30. Dryhurst, G. \& Elving, P. J. Electrochemical oxidation-reduction paths for pyrimidine, cytosine, purine and adenine: Correlation and application. Talanta 14, 855-874 (1969).

31. Psciuk, B. T., Lord, R. L., Munk, B. H. \& Bernhard Schlegel, H. Theoretical determination of one-electron oxidation potentials for nucleic acid bases. J. Chem. Theory Comput. 8, 5107-5123 (2012).
32. Sevilla, M. D., Van Paemel, C. \& Zorman, G. Reactions of the cation and anion radicals of several DNA bases. J. Phys. Chem. 76, 3577-3582 (1972).

33. Liu, K. et al. Thermotropic liquid crystals from biomacromolecules. Proc. Natl Acad. Sci. USA 111, 18596-18600 (2014).

34. Liu, K. et al. Solvent-free liquid crystals and liquids from DNA. Chem. Eur. J. 21, 4898-4903 (2015).

35. Rokhlenko, Y., Cadet, J., Geacintov, N. E. \& Shafirovich, V. Mechanistic aspects of hydration of guanine radical cations in DNA. J. Am. Chem. Soc. 136, 5956-5962 (2014).

36. Candeias, L. P. \& Steenken, S. Structure and acid-base properties of one-electron-oxidized deoxyguanosine, guanosine, and 1-methylguanosine. J. Am. Chem. Soc. 111, 1094-1099 (1989).

37. Steenken, S. Purine bases, nucleosides, and nucleotides: aqueous solution redox chemistry and transformation reactions of their radical cations and $\mathrm{e}^{-}$and $\mathrm{OH}$ adducts. Chem. Rev. 89, 503-520 (1989).

38. Joy, A., Ghosh, A. K. \& Schuster, G. B. One-electron oxidation of DNA oligomers that lack guanine: reaction and strand cleavage at remote thymines by longdistance radical cation hopping. J. Am. Chem. Soc. 128, 5346-5347 (2006).

39. Schiemann, O., Turro, N. J. \& Barton, J. K. EPR detection of guanine radicals in a DNA duplex under biological conditions: selective base oxidation by $\mathrm{Ru}(\text { phen })_{2} \mathrm{dppz}^{3+}$ using the flash-quench technique. J. Phys. Chem. B 104, 7214-7220 (2000).

40. Pawlicka, A. et al. Ionically conducting DNA-based membranes for eletrochromic devices. Synth. Met. 161, 2329-2334 (2011).

41. Kakibe, T. \& Ohno, H. Quasi-reversible electrochromic behavior of alkyl viologens dispersed mono-molecularly in double-stranded DNA chains. J. Mater. Chem. 19, 4960-4964 (2009).

42. Faul, C. F. J. \& Antonietti, M. Ionic self-assembly: facile synthesis of supramolecular materials. Adv. Mater. 15, 673-683 (2003).

43. Kato, T., Mizoshita, N. \& Kishimoto, K. Functional liquid-crystalline assemblies: self-organized soft materials. Angew. Chem. Int. Ed. 45, 38 (2006)

44. Stephen, M. Self-assembly and transformation of hybrid nano-objects and nanostructures under equilibrium and non-equilibrium conditions. Nat. Mater. 8, 781-792 (2009).

45. Alemdaroglu, F. E., Ding, K., Berger, R. \& Herrmann, A. DNA-templated synthesis in three dimensions: introducing a micellar scaffold for organic reactions. Angew. Chem. Int. Ed. 45, 4206-4210 (2006).

46. Pisula, W. et al. Relationship between core size, side chain length, and the supramolecular organization of polycyclic aromatic hydrocarbons. Chem. Mater. 17, 4296-4303 (2005).

47. Servers, N. J. Freeze-fracture electron microscop. Nat. Protoc. 2, 547-576 (2007).

\section{Acknowledgements}

This research was supported by the European Union (European Research Council Starting Grant and STREP project MICREAGENTS), the Netherlands Organization for Scientific Research (NWO-Vici, NWO-Echo), the Zernike Institute for Advanced Materials and U.S. National Science Foundation Grants DMR1207606 and MRSEC DMR1420736.

\section{Author contributions}

K.L. and A.H. designed the research; K.L., J.V., J.Y.G., A.O.P., M.S., J.S., D.C., W.Z. and A.M. performed the research; K.L., J.V., J.Y.G., A.O.P., M.S., J.S., D.C., W.Z., A.M., W.P., B.N., T.T.M.P., N.A.C. and A.H. analysed the data; and K.L., J.Y.G., J.V., D.C., W.P., B.N., T.T.M.P., N.A.C. and A.H. wrote the paper.

\section{Additional information}

Supplementary Information accompanies this paper at http://www.nature.com/ naturecommunication

Competing financial interests: The authors declare no competing financial interests

Reprints and permission information is available online at http://npg.nature.com/ reprintsandpermissions/

How to cite this article: Liu, K. et al. Controlling the volatility of the written optical state in electrochromic DNA liquid crystals. Nat. Commun. 7:11476 doi: 10.1038/ ncomms11476 (2016)

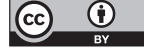

This work is licensed under a Creative Commons Attribution 4.0 International License. The images or other third party material in this article are included in the article's Creative Commons license, unless indicated otherwise in the credit line; if the material is not included under the Creative Commons license, users will need to obtain permission from the license holder to reproduce the material. To view a copy of this license, visit http://creativecommons.org/licenses/by/4.0/ 